\title{
A (DES)CONSTRUÇÃO DO “EU” N'OS CUS DE JUDAS
}

\author{
Juliana Garcia Santos da Silva* \\ Universidade Federal Fluminense
}

Resumo: Este trabalho tem como objetivo trazer à discussão o tema da composição do "eu" dentro da ficção de caráter autobiográfico Os cus de Judas (1979), do escritor português António Lobo Antunes. Para atender ao proposto, faz-se necessário avaliar a maneira como o autor tece seu discurso, no que tange à configuração da subjetividade associada à imagem (des)feita pela voz predominante do texto, que se dedica, durante uma noite taciturna regada à uísque, a jorrar sentimentos, sensações, receios e anseios. Conforme a obra envereda para o desvendamento do "eu" a partir de uma escrita memorialística, somos apresentados ao íntimo de alguém que compartilha do cenário caótico derivado da guerra colonial em Angola. Pensar em analisar o caráter do personagem a partir do que ele próprio conta é pertinente por nos permitir compreender como é configurado o pensamento contemporâneo que, por conseguinte, delineia as formas de arte. Como auxílio teórico preponderante, serão referenciados Stuart Hall, cujo foco selecionado é a noção de identidade, Walter Benjamin, por suas colocações acerca de narrador, Paula Sibilia pelo seu estudo em prol da manifestação do íntimo, e Michel Foucault pelas observações a respeito da individualização.

Palavras-chave: "Eu". Configuração da subjetividade. Escrita memorialística. Pensamento contemporâneo.

\author{
Dentro de si mesmo \\ mesmo que lá fora \\ fora de si mesmo \\ mesmo que distante \\ e assim por diante \\ de si mesmo, ad infinitum \\ $[\ldots]$ \\ (GIL, Gilberto. Meditação)
}

Esta obra está licenciada sob uma Licença Creative Commons.

\footnotetext{
* Mestre em Letras (UFF). Área de atuação em Literaturas de Língua Portuguesa: Literatura Portuguesa e Africana.
} 


\section{Introdução}

Há algum tempo, o sujeito por detrás da voz que se ergue em meio à narrativa é deixado de lado, ou melhor, é desprezado por sugestão das novas ou modernas teorias literárias advindas com o século XX erguidas para questionar as correntes oitocentistas, consideradas ultrapassadas. No entanto, a tendência à ficcionalização das experiências do locutor ou enunciador, percebida no âmbito da produção literária contemporânea, revela, intrigantemente, um gosto pela escrita de si. Sendo assim, testemunhamos o apogeu das narrativas de cunho subjetivo que propiciam, por vezes, a discussão acerca de uma identidade fragmentada ou mesmo perdida, típica de um contexto de crise, na medida em que privilegiam refletir sobre esse "eu”. Em razão dessa alteração de estilo percebida, comenta Stuart Hall em A identidade cultural na pós-modernidade:

\footnotetext{
A assim chamada "crise de identidade" é vista como parte de um processo mais amplo de mudança, que está deslocando as estruturas e processos centrais das sociedades modernas e abalando os quadros de referência que davam aos indivíduos uma ancoragem estável no mundo social. (HALL, 2006, p.7)4
}

O conflito existencial e a questão da identidade ganham voz nas obras contemporâneas ou pós-modernas, se pensadas como aquelas que denunciam a derrocada da modernidade, nos convidando a contemplar nossos medos, frustrações, angústias, e nossa natureza bruta e confusa, - velada e sufocada pelas regras da civilização - transformada em espetáculo, conforme veremos adiante.

\section{O desnudar do “eu” na ficção}

A exemplo de ficção autobiográfica que nos permite repensar e questão da crise de identidade, avaliemos Os cus de Judas em que o autor António Lobo Antunes, relata, por meio de um narrador-personagem melancólico, angustiado, frustrado e pessimista, sua atuação como médico, em meio à guerra colonial em Angola, denunciando, de forma verborrágica, o que foi obrigado a assistir. Lançando mão da memória, esse sujeito, então ficcional, revê experiências que lhe deixaram marcas indeléveis, que servem, pois, de subsídio para a (de)formação de sua essência e ao desenvolvimento da trama. A seguir, o momento em que embarcam rumo aos "cus de Judas", designação que referencia o cenário do duelo, espaço esse remoto e, supostamente, à margem da civilização: 
[...] Lisboa principiou a afastar-se de mim num turbilhão cada vez mais atenuado de marchas marciais em cujos acordes rodopiavam os rostos trágicos e imóveis da despedida, que a lembrança paralisa nas atitudes do espanto. [...] e eu perguntava a mim próprio o que fazíamos ali, agonizantes em suspenso no chão de máquina de costura do navio, com Lisboa a afogar-se na distância num suspiro derradeiro de hino. Subitamente sem passado, com o porta-chaves e a medalha de Salazar no bolso, de pé entre a banheira e o lavatório de quarto de bonecas atarraxados à parede, sentia-me como a casa dos meus pais no Verão, sem cortinas, de tapetes enrolados em jornais, móveis encostados aos cantos cobertos de grandes sudários poeirentos, as pratas emigradas para a copa da avó, e o gigantesco eco dos passos de ninguém nas salas desertas. (ANTUNES, 2003, p. 21)

Como vemos, já de início, o narrador-personagem anuncia a tragédia que está por vir, sentida e demonstrada através dos rostos daqueles que foram convocados à luta em nome da manutenção da metrópole. Mais ainda: revela um desconforto proveniente do contexto a que foi submetido - porque a guerra não lhe era coerente - e do vazio que tomava conta de seus pensamentos. Nesse momento, o sujeito que nos orienta pela narrativa principia um processo de mutação que nos remete à ideia de homem sem-lugar e identidade fixa, apresentado no decorrer de seu contar, direcionado a uma estranha, madrugada a fora, em um bar, um busca de um sentido para seu ser e estar no mundo.

As condições da viagem a qual foram lançados os soldados de Portugal maltratavam a tripulação que se via obrigada a adaptar-se e a resistir. Notemos, a seguir, que a batalha começa desde iniciada a trajetória dos escolhidos pela nação a caminho das terras "viciosas" por um ideal que não lhes servia de justificativa ou valia a pena:

[...] do porão onde os soldados se comprimiam subia um bafo espesso de vomitado, odor pra mim esquecido desde os meios-dias remotos da infância, quando, na cozinha, à hora das refeições, se agitavam à volta da minha sopa relutante as caretas alternadamente persuasivas e ameaçadoras da família, [...] (ANTUNES, 2003, p. 22)

A escolha pela sinestesia em "[...] subia um bafo espesso de vomitado [...]" levanta sensações e odor, resgatados pela memória, contribuindo para transmitir ao leitor a atmosfera aviltante da situação a qual estava sujeito o enunciador, trazendo à tona lembranças que este tinha impelido ao esquecimento, o que o faz vasculhar seu passado.

Em $O$ narrador, Walter Benjamin lembra-nos que a narrativa, enquanto fonte de experiência transmitida de geração a geração, tem como características comuns o senso prático e uma dimensão utilitária. Em outras palavras, que nos servem de premissa: “O narrador retira da experiência o que ele conta: sua própria experiência ou a relatada pelos outros. E incorpora as coisas narradas à experiência dos seus ouvintes". (BENJAMIN, 1994, p. 201) Aquele que nos conduz pel'Os cus de Judas organiza seu enredo a partir das próprias experiências, recorrendo à memória e, por conseguinte, selecionando os fatos sob uma 
perspectiva subjetiva. Porém, ao dedicar-se à eleição das ações perde de vista seu tom de "verdade". Quanto à dimensão utilitária de seu olhar voltado para si, vale dizer que este corresponde à tentativa de reconhecer-se. $\mathrm{O}$ (re)conhecimento de si somado à denúncia das atrocidades da guerra configuram, então, um possível e relevante propósito da opção pela ficção autobiográfica, abrindo espaço para a expressão do que promove as aflições do "eu" delator catártico:

Outro Vodka? É verdade que não acabei o meu, mas neste passo da minha narrativa perturbo-me invariavelmente, que quer, foi há seis anos e perturbo-me ainda: descíamos do Luso para as Terras do Fim do Mundo, [...] a dois mil quilômetros de Luanda, Janeiro acabava, chovia, e íamos morrer, íamos morrer e chovia, chovia, sentado na cabina da caminhoneta, ao lado do condutor, de boné nos olhos, o vibrar de um cigarro infinito não mão, iniciei a dolorosa aprendizagem da agonia. (ANTUNES, 2003, p. 42-43)

Mesmo que sob o efeito do álcool para encorajá-lo, o narrador de Lobo Antunes demonstra desejo de expor o que o incomoda, o perturba e lhe tira o sono. Aqui, o senso prático consiste em verbalizar sua norma de vida fragmentária e decadente, que assume a ideia de mal tempo ao enfatizar que "chovia". Segundo conta, nas Terras do Fim do Mundo, onde os minutos pareciam não passar e a morte se apresentava como certa, o "eu" deu início à “dolorosa aprendizagem da agonia”, o que significa deduzir que em África, esse sujeito é consideravelmente modificado.

Ao escrever sobre si, o enunciador pretende explorar-se e exibir suas falhas e feridas, ainda abertas, como quem deseja dizer ao mundo que parte daquilo que se tornou é produto do meio, ou seja, é resultado do que foi experimentado. Além disso, ao extravasar angústias e dividir o fardo da guerra com o ouvinte, no caso da leitura, com o leitor, incita o interlocutor a participar do espetáculo por ele produzido e a examinar os valores que compõem o alicerce dessa sociedade. Logo, a ficção autobiográfica, ao propiciar o resgate da memória, promove o revisitar da história deste "eu" e do "outro". Com isso, aquele visa situar-se no tempo e no espaço, enfim, busca encontrar-se e estabelecer-se como "Ser": "Ao falar de si, ao pensar sobre si, ao escrever sobre si, o sujeito está se multiplicando, está colocando em xeque sua unidade." (SANTOS, 2001, p. 18)

A tensa voz, que há certa altura da trama parece vomitar as ações, deixa transparecer que o conflito em Angola lhe tirou os véus que encobriam seu olhar, proporcionando-lhe consciência e, portanto, certa lucidez que lhe possibilita enxergar a arbitrariedade como regem seu país, feito opressor e, inevitavelmente, falido: 
[...] sentia-me melancolicamente herdeiro de um velho país desajeitado e agonizante, de uma Europa repleta de furúnculos de palácios e pedras da bexiga de catedrais doentes, confrontado com um povo cuja inesgotável vitalidade eu entrevira já, anos antes, no trompete solar de Louis Armstrong, expulsando a neurastenia e o azedume com a musculosa alegria do seu canto. A essa hora, na minha cidade castrada pela polícia e a censura, as pessoas coagulavam-se de frio nas paragens dos autocarros, a soprarem adiante da boca o vapor de água dos balões das legendas de uma história de quadrinhos que o Governo proibia. (ANTUNES, 2003, p. 57)

O cenário montado pela ditadura, as insatisfações com esse governo repressor e os estilhaços do choque em Angola minam a narrativa de Lobo Antunes sob a forma de questionamentos ainda em processo de assimilação, gerando um sujeito em crise mediante à falta de razões que justifiquem sua atuação nos confins de África, e à precariedade de suas instalações, somada ao constante risco de morte pelas emboscadas em terras desconhecidas:

$\mathrm{O}$ que fizeram do meu povo, $\mathrm{O}$ que fizeram de nós aqui sentados à espera nesta paisagem sem mar, presos por três fieiras de arame farpado numa terra que nos não pertence, a morrer de paludismo e de balas cujo percurso silvado se aparenta a um nervo de nylon que vibra, alimentados por colunas aleatórias cuja chegada depende de constantes acidentes de percurso, de emboscadas e de minas, lutando contra um inimigo invisível, contra os dias que se não sucedem e indefinidamente se alongam, contra a saudade, a indignação e o remorso, contra a espessura das trevas opacas tal um véu de luto, e que puxo para cima da cabeça a fím de dormir, como na infância utilizava a bainha do lençol para me defender das pupilas de fósforo azul dos meus fantasmas. (ANTUNES, 2003, p. 67)

Longe de sua terra natal e preso a essa situação degradante, o sujeito em questão demonstra indignação, remorso, luto e experimenta o medo. Verificamos que o espaço contribui para a formação deste "eu" atormentado pela experiência do caos proporcionado pelo embate entre seu país e Angola e financiado por interesses capitalistas que o lançaram, sob a alegação do patriotismo, à velha colônia. Quem realmente é não lhe faz sentido. Sua unidade se desmancha no ar, suas certezas são fugidias. Não é mais aquele homem rumo ao cumprimento de seu dever, tampouco um herói. O narrador se apresenta como alguém insignificante e solitário, fruto das amarguras da guerra:

Talvez que a guerra tenha ajudado a fazer de mim o que sou hoje e que intimamente recuso: um solteirão melancólico a quem se não telefona e cujo telefonema ninguém espera, tossindo de tempos a tempos para se imaginar acompanhado, e que a mulher a dias acabará por encontrar sentado na cadeira de baloiço em camisola interior, de boca aberta, roçando os dedos roxos no pelo cor-de-novembro da alcatifa. (ANTUNES, 2003, p. 69)

Como podemos notar, na obra aqui em evidência, prevalece a figura do anti-herói que faz uso das palavras para exortar seus traumas e inquietações. À medida que consulta a memória e se aprofunda nos fatos, o sujeito que nos guia pelas malhas textuais, nos 
impressiona com a imagem que faz de si próprio e com sua descrença na civilização, haja vista o esvaziamento de valores grandiloquentes:

Não, a sério, a felicidade, esse estado difuso resultante da impossível convergência de paralelas de uma digestão sem azia com o egoísmo satisfeito e sem remorsos, continua a parecer-me, a mim, que pertenço à dolorosa classe dos inquietos tristes, eternamente à espera de uma explosão ou de um milagre, qualquer coisa de tão abstracto e estranho como a inocência, a justiça, a honra, conceitos grandiloquentes, profundos e afinal vazios, que a família, a escola, a catequese e o Estado me haviam solenemente impingido para melhor me dominarem, para extinguirem, se assim me posso exprimir, no ovo, os meus desejos de protesto e de revolta. (ANTUNES, 2003, p. 148)

Mesmo as instituições socioculturais não escapam do julgamento cortante do relator, sendo por ele consideradas manobras governamentais lançadas mão a fim de sufocarem, reprimirem, limitarem sua força. Logo, vê-se impedido - senão por meio do relato e/ou da escrita - de manifestar seus "desejos de protesto e de revolta". Mais adiante de seu discurso, põe em relevo a animalização do homem pela submissão agregada à barbárie experimentada: “[...] a guerra tornou-nos em bichos, percebe, bichos cruéis e estúpidos ensinados a matar [...]" (ANTUNES, 2003, p. 150) Como é notado, O sujeito é reduzido ao estado animalesco deixando sobressair, devido àquele momento pessimista, o caráter agressivo inerente ao ser humano que, em casos como esses onde a dignidade está perdida e a humanidade se esvai, traz-nos à mente uma frase antiga proferida por Plauto - homo homini lupus - que vai sugerir essa selvageria natural do homem. A seguir mais uma passagem que corrobora a pertinência de tais colocações:

Trazíamos vinte e cinco meses de guerra nas tripas, de violência insensata e imbecil nas tripas, de modo que nos divertíamos mordendo-nos como os animais se mordem nos seus jogos, nos ameaçávamos com as pistolas, nos insultávamos furibundos, numa raiva invejosa de cães, nos espojávamos, latindo, nos charcos da chuva, misturávamos comprimidos para dormir no uísque da Manutenção, e circulávamos a cambalear pela parada, entoando em coro obscenidades de colégio. (ANTUNES, 2003, p. 209)

Retomando Stuart Hall, cabe acrescentar que, ao contrário do homem da sociedade moderna, o indivíduo pós-moderno perde um "sentido de si" também conhecido como deslocamento ou descentração dos indivíduos tanto do seu lugar social e cultural quanto de si mesmos. Assim:

O sujeito previamente vivido como tendo uma identidade unificada e estável, está se tornando fragmentado; composto não de uma única, mas de várias identidades, algumas vezes contraditórias ou não resolvidas. Correspondentemente, as identidades, que compunha as paisagens sociais "lá fora" e que asseguravam nossa conformidade subjetiva com as "necessidades" objetivas da cultura, estão entrando em colapso, como resultado de mudanças estruturais e institucionais. O próprio 
processo de identificação, através do qual nos projetamos em nossas identidades culturais, tornou-se mais provisório, variável e problemático. (HALL, 2006, p. 12)

O narrador de Lobo Antunes, ao se enquadrar na condição pós-moderna, problematiza o processo civilizatório, seu país, e a si próprio numa tentativa desenfreada de explorar sua essência. Em ruínas e acuado, após vivenciar dias difíceis, é levado a questionar o sentido da vida, o sentido das coisas, a reavaliar seus princípios e a propensão do homem à barbárie no momento em que se percebe obrigado a se despir das máscaras sociais que tanto lhe dão segurança e conforto:

[...] o meu egoísmo queria regressar inteiro e depressa [...] regressar e esquecer e retomar o hospital e a escrita e a família e o cinema ao sábado e os amigos como se nada me tivesse, entretanto, sucedido [...] Era tudo mentira e acordei, e, todavia, entende, em noites como esta, em que o álcool me acentua o abandono e a solidão e me acho no fundo do poço interior demasiado alto, demasiado estreito, demasiado liso, surge dentro de mim, tão nítida como há oito anos, a lembrança da cobardia e do comodismo que cuidava afogados para sempre numa qualquer gaveta perdida da memória, e uma espécie de, como exprimir-me? remorso leva-me a acocorar-me num ângulo do meu quarto como um bicho acossado, branco de vergonha e de pavor, aguardando, de joelhos na boca, a manhã que não chega. (ANTUNES, 2003, p. 163)

Seus encontros consigo mesmo e com seus temores, nutridos pela frustração, pela solidão e pela culpa, lhe conferem o mal-estar difundido através de expressões do tipo "me acho no fundo do poço interior", culminando no retrato de um íntimo devastado pelo remorso. António Lobo Antunes apresenta uma persona que tem sua formação comprometida por “desvalores", um tipo de herói às avessas, como já mencionado, surgido de um misto de realidade e ficção. Seu escrever tenta dar conta da profunda perplexidade de quem vivenciou a guerra, enfim, do incomensurável. Na escrita, aflora o inesquecível que, agora, passado o tempo, assume uma forma transmissível. Ao narrador-personagem cabe a tarefa de traçar sua precária trajetória com o auxílio do ir e vir da memória associando, inclusive cheiros, imagens e fatos de sua fase adulta à sua infância. Ainda que em uma autobiografia, e por mais honesto que o autor queira ser, há uma seleção de imagens de si mesmo que deseja projetar por meio de um "eu" simulado. Logo, identificamos a construção de um sujeito ficcional, cuja intimidade é dada como um espetáculo bárbaro.

A narrativa convoca seus leitores à revisão de valores e sugere certa descrença na humanidade a partir de um tenso e intenso apelo às sensibilidades, deixando transparecer a natureza hostil do protagonista que se confessa vulnerável e aturdido por incertezas e dúvidas existenciais. Enfim, ao tratar do declínio de um "eu” trata do declínio da civilização, tema que comumente ganha forma nas manifestações artísticas elaboradas a partir da segunda metade do século XX, período da crise originária da transição dolorosa e interrogativa estabelecida 
entre a decadência da modernidade e o surgimento de uma pós-modernidade. Por assim dizer, a contemporaneidade, contaminada por sentimentos que aludem à desintegração, passa a ser percebida e representada a partir de um cenário confuso, perturbador, que detêm uma amostra de nossa mentalidade.

De acordo com Paula Sibilia (2008) estaríamos assistindo a importantes transformações na maneira com que os indivíduos configuram e vivenciam suas experiências subjetivas que parecem se ancorar na exterioridade, naqueles sinais visíveis emitidos por um corpo, tal como na conquista da tão almejada visibilidade. Ainda à luz das contribuições de Sibilia, convém assinalar que acompanhamos mudanças significativas ocorridas nas mais diversas áreas da sociedade e atravessamos mutações igualmente profundas na definição da subjetividade individual. Isso nos leva a crer que "o show do eu", aqui representado pela narrativa de António Lobo Antunes, é justificado por tendências confessionais, exibicionistas e performativas que nutrem novas modalidades de construção subjetiva e de manuseio identitário, que visa à obtenção de um efeito: o reconhecimento nos olhos do outro e, sobretudo, o desejado fato de ser visto. Entretanto, essa constituição de si como personagem visível, denotaria, segundo a autora, um evidente pavor da solidão, e, por conseguinte, um flagrante tipo contemporâneo de fragilidade:

Não chega, a manhã, não vai chegar nunca, [...] achamo-nos condenados, você e eu, a uma noite sem fim, espessa, densa, desesperante, desprovida de refúgios e saídas, um labirinto de angústia que o uísque ilumina de viés da sua claridade turva segurando os copos vazios na mão como os peregrinos de Fátima as suas velas apagadas, sentados lado a lado no sofá, ocos de frases, de sentimentos, de vida, a sorrir um para o outro caretas de cães de faiança numa prateleira de sala, de olhos exaustos por semanas e semanas de apavoradas vigílias. (ANTUNES, 2003, p. 164)

\section{Considerações finais}

Face ao exposto, observa-se que a ficção de Lobo Antunes, mostra a trajetória de um cético perturbado pela sensação de estar sitiado em sua própria vida considerada vazia e tomada por insatisfações, que vão contribuir para a falta de esperanças. Esse indivíduo, além de nos advertir para o sistema caduco e asfixiante ao qual estamos subjugados, permanece entregue à sua condição de ruína, pois não encontra forças ou coragem para transformar sua realidade. Enxerga-se como alguém sem iniciativa que se conformou com sua vida e que não está disposto a lutar seja lá qual for a causa:

[...] os soldados julgavam-me capaz de os acompanhar e de lutar por eles, de me unir ao seu ingénuo ódio contra os senhores de Lisboa que disparavam sobre nós as balas envenenadas dos seus discursos patrióticos, e assistiram enojados à minha 
passividade imóvel, aos meus braços pendentes, à minha ausência de combatividade e de coragem, à minha pobre conformação de prisioneiro. (ANTUNES, 2003, p. 203)

Rendido à bebida porque deseja ludibriar a lucidez, o personagem investigado neste trabalho, mesmo criado para ser porta-voz da experiência do autor, não equivale a um desenho fidedigno deste, já que sua formatação se deve à preocupação com um fazer estético, ou seja, com o propósito de articular a escrita em prol da elaboração de um texto ficcional. Contudo, fica reconhecida a importância do refletir sobre a organização do "eu" associada à noção do autor em uma narrativa de espécie autobiográfica, visto que nos direciona - como propõe Foucault em seu texto $O$ que é um autor? de 1969 - a um momento crucial da individualização na história das ideias, dos conhecimentos, das literaturas, e que se estende à história da filosofia e das ciências. Afinal, pondo em xeque a relação texto-autor, no sentido de como o primeiro aponta para o segundo, que lhe é aparentemente exterior, e diante da averiguação do "eu" como matéria de ficção, temos garantido reconhecer a nós mesmos, nossos gostos e perspectivas.

\section{Referências}

ANTUNES, António Lobo. Os cus de Judas. Rio de Janeiro: Objetiva, 2003.

BENJAMIN, Walter. Magia e técnica, arte e politica: ensaios sobre literatura e história da cultura. Trad. Sérgio Paulo Rouanet. 7.ed. São Paulo: Brasiliense, 1994, (Obras escolhidas, v. 1)

FOUCAULT, Michel. O que é um autor? Lisboa: Vega, 2009.

HALL, Stuart. A identidade cultural na pós-modernidade, Rio de Janeiro: Dp\&a Editora, 2006.

SANTOS, Luís Alberto Brandão. Sujeito, tempo e espaço ficcionais. São Paulo: Martins Fontes, 2001.

SIBILIA, Paula. O show do eu: a intimidade como espetáculo. Rio de Janeiro: Nova Fronteira, 2008.

[Recebido em julho de 2012 e aceito para publicação em outubro de 2012]

\section{The (de) construction of "I" n'Os cus of Judas}


Abstract: This work aims to bring to discussion the issue of composition of "I" in the autobiographical fiction of the asses of Judas (1979), the Portuguese writer António Lobo Antunes. To meet the proposed, it is necessary to assess how the author weaves his speech regarding the configuration of subjectivity associated with the image (un)done by the dominant voice of the text, which is engaged during a night brooding watered the whiskey, gushing feelings, feelings, fears and anxieties. As the work is appealing to the unveiling of the "I" from a written memorial, we are introduced to the intimate with someone who shares the chaotic scenario derived from the colonial war in Angola. Thinking analyze the character of the character from what he account is relevant for allowing us to understand how it is configured contemporary thought, therefore, outlines the forms of art. As an aid predominant theory, will be referred to Stuart Hall, whose focus is selected the notion of identity, Walter Benjamin, for his statements about the narrator, Paula Sibilia for his study in favor of the manifestation of the intimate, and Michel Foucault by observations of individualization.

Keywords: "I". Configuration of subjectivity. Writing memoirs. Contemporary thought.

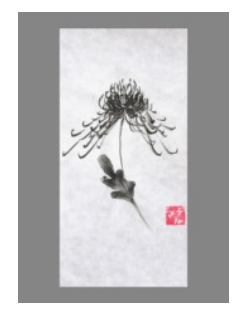

